(En)activist Drag: Kings reflect on Queerness, Queens, and Questionable Masculinities

(En)activist Drag: Kings reflect on Queerness, Queens, and Questionable Masculinities

\author{
Lisbeth A. Berbary \\ Corey W. Johnson \\ University of Waterloo
}

This is an Accepted Manuscript of an article published by Taylor \& Francis in Leisure Sciences on July 20 2016, available online:

http://www.tandfonline.com/10.1080/01490400.2016.1194791. 
Kings reflect on Queerness, Queens, and Questionable Masculinities

In clubs, bars, private parties, TV shows, and movies, the drag queen has occupied an important space in conceptualizations of gender in America. In recent years, media attention to drag queens has increased dramatically (Schact \& Underwood, 2004; Vidal-Ortiz, 2008; Zervigon, 2009) "transforming the once-hidden leisure activity of the Lesbian, Gay, Bisexual, Transgender, and Queer (LGBTQ) community into a publicly recognized leisure practice performed primarily in leisure spaces for the purposes of entertaining others" (Barnett \& Johnson, 2013, p. 679). Media products like RuPaul’s Drag Race; Too Wong Foo (Brown, 1995) and The Adventures of Priscilla, Queen of the Desert (Hamlin, 1994); and popular books like Diary of a Drag Queen (Harris, 2005) have all worked to shift discussions of gender and gender performance into the day-to-day consciousness of mainstream America.

In academia, attention to drag and (re)conceptualizations of gender began even prior to the media boom given Esther Newton's (1972) classic study of female impersonators in America, Judith Butler's (1990; 1993) theoretical discussions of drag as parody, and Halberstam's (1998) exploration of female masculinity, all of which sparked debate and increased research around the intersections of drag, gender, and performativity. Yet, despite recent media attention and increased research on drag queens, little attention is yet to be given in leisure studies to drag queens' counter-parts—drag kings, “anyone (regardless of gender) who consciously makes a performance out of masculinity (Halberstam, 1999, p.16), though typically thought of as females who dress up in recognizable male/masculine costume to perform theatrically.

\section{Drag Kings}

Contemporary drag kings “(as opposed to the male impersonator that preceded them in Western culture by at least a century)” (Surkan, 2003, p. 162) have been visible since the mid- 
Kings reflect on Queerness, Queens, and Questionable Masculinities

80s, but have only come into mainstream popularity since the late 1990s (Rupp, Taylor, Shapiro, 2010; Volcano \& Halberstam, 1999). Over the last few decades, drag king performances have evolved considerably, moving into new venues beyond entertainment to also include participatory, activist, multi-layered acts integrated with fluid complexity, social theory, and challenges to traditional notions of binary gender (Surkan, 2003). Drag king shifts into popular culture and social complexity were partially ignited by Halberstam's books, Female Masculinity and The Drag King Book—both of which worked to develop complex understandings of the performativity of gender as it engaged with female masculinity, artistic expression, and the production of self, both on and offstage. Understanding this shift within contemporary drag king culture requires exploring a nexus across theory, performance, and conceptualizations of gender and power. Therefore, in order to illuminate the complex experiences of contemporary drag king performers and their understandings of gender, we specifically look to the narrative data collected with eight kings located throughout the US and Canada.

\section{Methodology}

Given the options surrounding qualitative research, narrative inquiry seemed most appropriate for the study of drag performers because of its inherent potential to position participant's own understanding of their gendered subjectivity at the forefront; illuminate examples of agency and cultural contestation; reveal human transformation; and, promote advocacy through connection with the reader. This approach also may empower our participants by affirming their individual gendered experiences (Costa \& Matzner, 2007; Lewis \& Johnson, 2011).

Several popular styles of narrative inquiry are used in qualitative research. Specifically, we chose to infuse "biographical" aspects into the "experience-centred" approach described by 
Kings reflect on Queerness, Queens, and Questionable Masculinities

Squire (2008) because the experience-centred narrative “...assumes that narratives: are

sequential and meaningful; are definitely human; 're-present' experience, reconstituting it, as well as expressing it; (and,) display transformation and change” (p. 42). Narrative methods put the participant in the centre of the research process as the "expert" of their own life story, which sharply contrasts to traditional methods of the researcher taking full control, considering themselves as the 'experts' to guide the participants' stories (Riessman, 2007; Squire, Andrews, \& Tamboukou, 2008). This approach is especially pertinent to our focus on individuals' meaning making processes around life events in relation to gender expressions because gender, while constituted by discourse, is materially experienced in a personal and individualized manner (Butler, 1990). The methodology used in this project then was deliberately selected to encourage our participants' telling of their personal narratives to answer the following research questions: 1) What are the important stories and events that have shaped the performer's drag identity? 2) What are the daily joys and struggles of being a drag performer? 3) What is interesting or meaningful about managing a multiple-gendered identity? 4) What are the relationships between drag performers and the queer community in terms of activism, friendships, politics, and space?

Once ethics approval was secured, the second author (will be changed to name when published) used purposive and snowball sampling strategies to recruit queens and kings to be interviewed. In order to capture complexity across social categories, a cadre of performers were recruited who represented the diversity of the drag community in terms of race/ethnicity, age, gender identity, sexual orientation, size of city, motivations for performing (career, charity, etc.) and length of career. However, the second author did want participants to have enduring involvement in drag and therefore specifically recruited those individuals who had at least five years of performance experience. Both locally, and when traveling for personal and professional 
Kings reflect on Queerness, Queens, and Questionable Masculinities

reasons, the second author would scour the web and Facebook to learn of the most popular drag performers in the city to be visited including Buffalo, San Diego, Dallas, Miami, Raleigh, Atlanta, and Toronto. Once identifying the primary performers in that city, the second author would "friend them" and email them requesting participation in the study. After a performer agreed to be interviewed, an interview was scheduled at a time and location of convenience, which included locations such as living rooms, hotel lobbies, restaurants, bars, and dressing rooms.

Narrative interviews were conducted in an unstructured format from 1-3 hours, where participants shared their stories in ways that allowed them to focus on what they felt was most appropriate and/or relevant, providing an opportunity for their stories to be heard in ways that might otherwise be dismissed or redirected during more semi-structured interviewing formats (Gysels, Shipman, \& Higginson, 2008; Riessman, 2007). It is this opportunity to tell the story often omitted from meta-narratives that makes narrative research a potential tool for mobilizing positive change through the telling of marginalized counter-stories (Mattingly \& Lawlor, 2000; Riessman, 2007). Furthermore, the narrative platform allows the participants to become "part of a written document - a testimony of what occurred at a particular moment of history” (Stuhlmiller, 2001, p. 75), at times increasing a sense of empowerment through the articulation of traditionally silenced stories (Mattingly \& Lawlor).

After all interviews were transcribed, the first author was brought on to collaborate on analysis, representation construction, and interpretation of the eight drag king interviews. Using a contextualizing analysis process, initial readings of the transcripts were done with special attention to a priori theory, research questions, and anomalies and repetition within the data. During initial readings, strong narratives grounded in the data were identified with an array of 
Kings reflect on Queerness, Queens, and Questionable Masculinities

repetitive concepts and themes from the data being explored within each. These identified narratives attended to ideas of: 1) Being Genderqueer; 2) All gender as performance; 3) Misogyny across drag; and 4) Drag as activism. Once identified as meaningful stories, the second author gathered quotes from across all eight transcripts for each story that needed to be told, creating storyboards of complied quotes. The second author then organized and reorganized quotes from across the transcripts to re-story them into a more visual/poetic, creative analytic narrative format that told the stories that needed to be told based on our research questions (Berbary, 2015; Boles \& Berbary, 2014; Parry \& Johnson, 2007). These final representations are grounded in the data and are an expression of aspects from each participants' stories, although creative devices such as repetition, visual structure, and emphasis have been added (Berbary, 2011; 2015). Rather than answer each research question separately, each representation integrated responses from across all four research questions to show the intersections of the complexities found within the messy lived experiences of participants as they simultaneously were shaped by the joys and struggles of being a drag performer within their community.

Below we present each of these visual/poetic narratives and then provide researcher interpretation as we thought with theory about our findings. Although in some ways our choice in representing data through this format disrupts the full length, linearly presented, individual narratives, this format allowed us to highlight the tensions, juxtapositions, and breadth of experiences of the participants in a way that brought attention to much of their stories' overarching messages. Finally, as scholars who fully engage with the crisis of representation and shifts towards creative analytic practices, we felt this format provided the potential to engage 
Kings reflect on Queerness, Queens, and Questionable Masculinities

readers in an aesthetically accessible and leisurely way that more traditional linear

representations might not (Berbary, 2011; 2015; Parry \& Johnson, 2007).

\section{Genderqueer: An “unspeakable” identity}

I carry my female body in more masculine ways, but I don't see myself as JUST-A-GUY because I'm not just a guy, I'm so much more than that. Gender is not binary. You don't have to be one way or another:

\section{high femme really masculine}

When I was first coming out I thought that I had

to choose a gender

and that's where I. got. stuck.

So I'd try to be masculine and feel closeted.

And I'd try to be feminine that that felt really restrictive, and what it came down to is that I'm just all over. I'm all over the spectrum.

I'm genderqueer.

Even with all my masculinity, I'm still a woman. I'm a genderqueer woman and that pushes boundaries. I'm not a lesbian, I'm not a gay man, I'm not really trans, I'm genderqueer. It's gender. It's hard. And I get it. More than anyone else I've ever really met, I get it.

I get men,

I get women,

I get in between,

I get it.

I can't be checked off in a nice little box of female or male.

So people are scared, attracted, uncomfortable, confused.

They don't know what to do with people right in the middle, in middle of transition,

in between the plane of gender, in the joy of not knowing.

Even the talk of "in-between" or "in the middle" just reinforces binaries...no matter what we say. Yet who's to say its masculine or feminine?

And, does it have to be?

And so how I perform my gender is in your face, I can't help it, I'm not trying to make anyone uncomfortable, I just am different. I just look different. I am different. I'm genderqueer. I'm walking around as a woman, dressed as a man, almost trans, but not trans... 
Kings reflect on Queerness, Queens, and Questionable Masculinities

So what am I?

It's a hard one to navigate. I present masculine, but I'm still a woman.

I'm both,

I'm all,

I'm genderqueer

and it's normal to me.

Genderqueer has only recently entered the lexicon of feminist scholars and activists. Despite the lack of a formal definition, at least a few characteristics are recognizable for people who identify as genderqueer such as individuals refusing to categorize as either male or female. Instead, genderqueer individuals may opt to identify "as both, or somewhere in between" (Beemyn, 2009) to challenge the male-female gender binary and the assortment of norms and roles that are associated with gender concepts. Some may also subsume this definition under the umbrella of transgender identity that can refer to "all individuals who live outside of normative sex/gender relations" (Namaste, 2000, p. 1). Whether transgender or genderqueer, the adoption of nonconforming identities by most of the participants worked to disrupt notions of drag kings as female bodied, female-identified individuals performing a gender in opposition to their day-today presentations. Such relational and situational understandings of gender are becoming more and more accepted within social theorizing of gender identities (Butler, 1990; Connell, 1995; Schacht, 1998). As Schacht (2000) noted, "the meanings attached to these social constructs can only be fully comprehended when they are simultaneously considered as relational contrasts of existence" (p. 254). In other words, meaning connected to terms such as male and female must always be under erasure, deterred, and compared against their difference (Derrida, 1976). Within the space of difference, the disconnections between either/or gender, embodiment, and performance caused a re-thinking of what it means to perform drag-moving away from the typical understanding of drag as a purposeful opposition between body, identity, and the staged gender performance - and moving towards an indefinable queer space. Rupp et al. (2010) acknowledged this as a space of "doing gender differently," noting that many drag kings transformed their identity as a result of performing as a drag king. Specifically, drag kings moved from "female to male gender or sex" and toward other gender non-conforming identities such as "genderqueer and Female To Male (FTM) identities" within these queer leisure spaces (p. 282). A queer space of this nature blurred binaries, dismantled the thinkability of 1:1 correspondences between inside/outside, male/female, authentic/inauthentic, and mind/body, and further complicated the social constructions of gender (Barad, 2007). The introduction and recognition of genderqueer subjectivity then complicated the definition of "drag king” as a female performing male — and instead worked to welcome the stage to "doing drag differently" by opening the term drag up to more than just those individuals performing binary gender "mismatches" between body/identity and performance.

\section{Doing drag: Gender as always a performance}

It's funny to me because a lot of trans guys who did drag before they transitioned decide not to do it anymore. They say:

"I feel like I'm making fun of myself or that I don't need to pretend anymore." 
I'm different. I go on. People ask me “why are you still performing since you transitioned?” Like how can it still be drag if I'm just dressing up as myself? As the gender I normally present as“a man performing masculinity?”

But for me the definition I give of drag is: a performance of gender.

It's about a performance that shows funny, comedic, or stereotypical aspects of gender, and makes people question:

this is what we see as male, but... is that really necessarily male?

Or can a female play that?

Or why is that thing only allowed for men?

To dance like a man? What does that even mean?

...so regardless of however you identify around gender you can still perform it. It doesn't have to be the opposite of how you present. Gender is not a binary and so as drag kings we can be a genderqueer society so...

If you're a fem performer and you want to perform femininity, you can at a drag king show.

If you're a man and you want to perform masculinity, you can at a drag king show.

If you're trans and you want to perform femininity, you can;

masculinity,

you can.

You can switch your gender up, you can do whatever, you can do burlesque; boilesque, you can do whatever you want.

We can reimagine masculinity or play with our effeminate sides. We can try a gender on. We can take up that space. We can show another realm of attraction, another path that

up. things

shakes We can interact with people genuinely and with respect, regardless of what gender roles we are in at that moment. We can show that we are pretty without it all. We can be the genders we'd like to see become in the world. We can perform gender. We can perform genders. We can.

So do it. Do drag with love, passion, and respect. Do it all? Yes we can.

Although many participants identified as genderqueer, there were also individuals who identified 
as or spoke about drag kings who identified with more traditional binary positions. In particular, participants spoke of different drag communities and individuals having various levels of acceptance of drag kings and queens who performed the gender that they lived out on a day-today basis otherwise known as bio kings and queens (Rupp et. al, 2010). Participants told stories of individuals who were questioned about their legitimacy as a drag performer when they had either taken part in gender re-assignment surgery and/or were now performing the gender that matched their body and/or simply were performing the gender that they identified with dailyregardless of body. For some, it somehow seemed less of a performance if your body/gender identity matched the gender you were performing on-stage. However, while there were various perspectives, participants reiterated that in many drag king communities, no matter how one identified, all gender was understood as a performance, a copy of a copy without an original (Baudrillard, 1981/1998). And so regardless of body or identity, getting up on stage always was a performance of some gender, just as one's day-to-day gender may be considered a performance. Therefore, all gender can be seen as drag (Butler, 1993).

\section{Navigating misogyny: Inequity in Queen vs. King drag}

We are set up for less fame because we perform in groups. Maybe it's our female socializationwe depend on one another. We don't get that notoriety like individual drag queens.

\section{And that's frustrating.}

I'm a performer too. I put my heart into it too. I work while on stage. I don't just put on a good face and lip-sync to success.

But what do we expect? Traditional gender roles rule even in Drag. A woman dressed as a man is a tomboy, mostly ignored. But a man dressed as a woman? A body with make-up, high heels, long hair... well "she" is a spectacle. A big deal! Deserving of attention. Anyone transforming into a beautiful women will be slathered with compliments. Dress like a guy, and not one....

\section{And that's frustrating.}

And the misogyny we put up with. Drag queen, big-barbies with their hyper-glamorized version of femininity - well some of them still hold onto their high level of privilege and entitlement that comes from being a man. Dress like a women, but you can't kick out the male privilege in them! They may be impersonating a woman, but they don't have to think like one---they can ignore the need to reflect on how to operate in a world run by men. Impersonate the glamour, ignore the inequality that comes along with it. Sometimes they even disrespect drag kings by still calling us "she" when on stage- try calling a drag queen "he" and see what happens!

\section{And that's frustrating.}

And then there is the misogyny that drag kings do themselves. Some drag kings think that just because they identify as a woman, when they aren't in drag its okay for them to portray certain aggressive roles on stage as a man. They're all about sex and objectifying women.

And that's frustrating. 
Kings reflect on Queerness, Queens, and Questionable Masculinities

But there are some of us who do drag differently.

We make drag political.

We ask what stories we want to tell about...

political systems, war, family issues, alcoholism?

What kind of space do we want to take up?

What kind of masculinity do we want to see in the world?

Why perpetuate negative views of masculinity?

Instead, let's challenge social norms and

provide positive presentations of various gender identities.

So, kings may have less notoriety,

less space,

and unequal pay...

but maybe we can make our moment count a little more,

maybe make it a little more precious.

And that's a little less frustrating.

Just as there were at times discrimination or questioning around the legitimacy of certain drag performers, drag kings spoke of the clear discriminatory interactions that they experienced with drag queens. The participants spoke of most drag queens thinking lesser of drag kings because of androcentrism, phallocentrism, and their inability to access hegemonic masculinity (Connell, 1995), therefore not granting kings the same legitimacy and prestige that the drag queens themselves enjoyed and acknowledged among one another. A common complaint that the drag kings had was that drag queens performed femininity and expected the privileges that they expected came with femininity — such as being told they were beautiful, being called she, getting appreciation for their style-yet queens simultaneously also still expected male privileges and maintained masculine privilege such as using space, intimidation, misogyny, and patriarchy to lay claim to drag stages, notoriety, and social and economic capital (Dolan, 1985;

Frye, 1983; Gagné and Tewksbury, 1996; Schacht, 1998, 2000, 2002a, 2002b; Tewksbury, 1993, 1994). At times, drag kings themselves participated in and even recognized their own complicity in hegemonic forms of both femininity and masculinity. Consequently, their "in your face" experiences of male privilege and misogyny led many of them to want to do their own drag differently to challenge normative forms of dominant masculinity — forcing them to question their own performances of masculinity and use of masculine privilege both in their drag and dayto-day lives.

\section{Doing drag deliberately: Activating change in/through gendered "en-activism"}

$$
\text { Drag opens things up. }
$$

Straight gay bi pan trans butch femme

We use drag to create $\leftarrow$ connections $\rightarrow$ across lines

Welcoming the most disenfranchised in the queer community. 
Kings reflect on Queerness, Queens, and Questionable Masculinities

Bringing education to straight people.

Welcoming all sexual and gender identities to share in connection;

to connect with one another.

Straight woman $\leftarrow \rightarrow$ gay man lesbian $\leftarrow \rightarrow$ straight man $\quad$ trans man $\leftarrow \rightarrow$ queer person

We use drag to show there's no black and ming in those moments of connection

Things change. Love becomes.

We connect, not repel.

we bring someone into us,

entertain them,

get their attention for the right reasons,

feed them what they want.

We use drag to change the ways we think about attraction as lines of desire are blurred.

Fluid identities, fluid presentations sharing space.

Encouraged by drag to be more fluid with their own selves

as they become who they are or who they want to be.

Offering different perspectives, supporting or reflecting trans identities, challenging stereotypes of gender, supporting genderqueer spectrumsthe breath of gender identity, the array of body types. Bringing things to light to validate one another.

We use drag to welcome, educate, create inclusive messages, and open conversations.

We use drag to brake down boxes,

make genderqueer safe spaces, reflect the queer community

change the way we are accepted, challenge the ways we are judged.

We use drag to encourage all the genders and sexualities we want to see in the world.

Drag kings often found themselves navigating misogyny as they attempted to make space for themselves within a drag queen-controlled performance space. Rupp et al (2010) also found such activist intentions in drag king performances stating that drag kings "performed in numbers with the intention of challenging their audience not only on issues of gender and sexuality, but race, class, body size, and war, to name a few (p. 287). Their interactions with drag queens' masculinities and general masculinities within the world led many of them to re-consider how they chose to take up and perform masculinity and present themselves as "gender outlaws" as an act of political resistance to hegemonic gender norms (Rupp et al, 2010, p. 288). They 
recognized the problems with heteronormative, hegemonic masculinities and often attempted to use drag as a space to perform such masculinity as parody to draw attention to absurdity and/or perform masculinity differently in a way that challenged constructions of normative white, middle class masculinity. Many theorists recognize that drag king performances influenced by queer theory are "transgressive actions that destabilize gender and sexual categories" by making visible the socially constructed nature of femininity, heterosexuality, and all hegemonic genders and sexualities (Butler, 1990, 1993; Garber, 1992; Lorber, 1994, 1999; Muñoz, 1999; Rupp \& Taylor, 2003). As such, drag king performances are "a form of resistance that undermines the assumed connections among heteronormative, hegemonic, and androcentric masculinity, femininity, and sexuality (Moloney \& Fenstermaker, 2002; Rupp et al., 2010).

Rather than simply reproduce what it "means to be a man," many participants saw their use of drag as an act of activism. Some felt their performance asked the audience to consider what else masculinity might be and what might feminine masculinity or masculine femininity look like. Others felt that their performance moved beyond notions of feminine and masculine and instead encouraged the consideration of a genderqueer space or even a genderless world. While not all drag king performances take an activist stance, many of our participants hoped that by enacting and embodying the "doing of gender differently," they might help breakdown normative gendered expectations and encourage others to think and act in more inclusive ways.

\section{Summary Discussion}

As interest in drag kings heightens, a stable definition of "who/what" is a drag king is continually disrupted. While it is often assumed by those outside of the community that drag kings must be lesbian and cisgender females (individuals who identify and present in-line with cultural expectations of their phenotype/biological body) in actuality the diversity of drag king performers is much more complex. Such complexity includes drag kings of various genders, sexualities, races, and other intersections. As Rupp et al. (2010) noted, “Drag kinging includes female-bodied individuals performing masculinity, transgender identified performers performing masculinity or femininity, and female identified individuals performing femininity, the latter known as 'bio queens'” (p. 276).

Unfortunately, popular American culture often ignores these complexities of identities and the ability to "do drag differently" in ways that re-create drag spaces, notions of gender, performance, and masculinity itself, within contexts defining what it means to do drag. However, 
Kings reflect on Queerness, Queens, and Questionable Masculinities

the kings interviewed clearly engaged with "doing drag differently" as they broke down binary thinking around gender and embodiment, masculinity and femininity, and inner truths and outer masks, all the while navigating—both subverting and/or reinforcing—complex societal expectations of gender and subcultural expectations for what it means to do drag. They negotiated their own identities, the ways they were perceived by others, how they were treated by drag queens, and what kinds of space they wanted to make for their own performances both on and off stage.

\section{(Re)conceptualing Normative Gender}

In particular, (re)conceptualizing gender though thinking more critically about drag, forces us to think differently about gender and recognize that it "has no ontological status apart from the various acts which constitute its reality” (Butler, 1990, p. 136). Rather, as the above narratives illustrated, the "ways in which kings were responding to and testing the limits of conceptualizations of gender” highlighted the performative of gender. Specifically, the external production of gender through signs and discourse was made legible, and the need for a constant repetition of those signs and discourses in order to secure a fixed perception of gender's "truth, stability, and depth” became clear. In other words, drag helps to show that rather than representing an inner truth, gender is simply a fabrication of power articulated onto the body through forms of corporeal repetition. Detached from ontological absolutes, gender roles prescribed by society then all become performative—legitimized as "real" through signs and discourses that bodies repeat in order to be "read" by others as gendered beings (Butler).

\section{Drag as Parody}

And if gender has no inner truth, but rather is performative, how do we come to know what expressions of gender in drag are "real, true, original and deep" and what expressions are 
Kings reflect on Queerness, Queens, and Questionable Masculinities

the performance? And this is the question deconstructed by Butler’s (1990) notion of drag as parody. She asked, which is the "truth” of a person's gender-their “deep” biological sex as man/woman or the performance of masculine/feminine on the "surface”? However, Butler questions even a metaphysical divide between depth and surface. In other words, the traditional lines of inner truth and outward appearance are deconstructed, troubling the existence of any depth or surface, true or original gender. Rather than there ever being “an original or primary gender identity,” Butler instead theorized that all gender is simply "the notion” of an original, rather than an actual original—-highlighting the fiction of gender through the imitation of it in drag. As Butler wrote, “In imitating gender, drag implicitly reveals the imitative structure of gender itself_-as well as its contingency” (p. 137). Therefore, drag forces us to reconsider relationships between sex/gender/self and binaries of male/female in any absolute, given, stable configuration.

Yet, although drag helps to reveal the fiction of gender-opening up the possibilities of “doing gender differently”_Butler (1993) later cautioned against an assumption that drag necessarily creates an inherently subversive alternative to taken-for-granted expectations of gender. Rather, she warned that "drag may well be used in the service of both the denaturalization and reidealization of hyperbolic heterosexual gender norms (Butler, 1993, p. 125).

\section{Drag as Subversion}

And how might kings we interviewed make sure to create subversive performances? Quite often the extent to which a king performance is considered subversive depends on the audience's read concerning the stability of the performers underlying gender identity. Surkan 
Kings reflect on Queerness, Queens, and Questionable Masculinities

(2003, p. 183) explained the “conundrums” of king subversion in relation to Butler's notions of drag as parody when she wrote,

If at the conclusion of the show, the king's masculine presentation is erased in a return to the feminine, the performance is seen to be an example of gender fluidity, but one that fails to subvert binary gender categories. On the other hand, if the stated masculinity is understood to be an extension of the performer's own female masculinity, the performance is a counter-demonstration of the fluidity of gender, but a transgression of the conventional sex/gender system, which maps masculine to male, feminine to female. Yet each of these scenarios relies on an understanding of the performer's prior gender identity as stable and recognizable as either masculine or feminine (butch or femme), which seems to carry us further away from Butler's description of drag as a parody of 'the notion of an original or primary gender identity.

Enactments that rely upon the acceptance of the same stable structures that Butler's parody rejects as "real” fail to successfully engage in discursively subversive practices without simultaneously upholding limiting notions of gender and sexuality. However, as we saw in our data, kinging that rejects such structure through complicating and layering performances, queering gender, challenging misogynist structures, and presenting non-normative sexualities instead make the parody of drag even more visible by showing the limits and cracks of normative gender identity. In particular, these multi-layered performances question the existence of normative gender identity as a necessity or requirement for drag, and help to subvert the expectations of status quo.

\section{Doing drag differently}

But what then happens when there is not a normative gender identity underlying drag? What happens when there is "no pretty girl” underneath masculine drag, but instead a "butch female masculinity performing male performing femininity” (Surkan, 2003, p. 172)? Such complexity "disengages masculinity from the male body" and reveals the series of layers that result in "a sophisticated queer performativity” (Surkan). This queer performativity calls into 
Kings reflect on Queerness, Queens, and Questionable Masculinities

question and opens up stable gender — even at times questioning the usefulness fluid gender as a replacement for normative conceptualizations. For example, while scholars often call for fluid gender, Halberstam (1998) warns that we must be cautious in such a call because, "If what we mean by saying gender is 'fluid' is simply that one can willfully slide from one end of the gender scale to the other, the stakes and the consequences are radically different for the actor or drag performer than for the gender deviant” (p. 166).

However, in our research we often found that the distinctions between drag performer and day-to-day "gender deviant" were blurred as queer performativity was enacted in multiple ways both on and off stage. Such blurring continues to show the complexity of contemporary drag, as current renditions shift between entertainment and identity, putting into question the relationships or equations such as sex/gender, masculinity/femininity, heterosexual/homosexual, depth/surface, outer/inner, stage/street, and butch/femme (Hennessey, 1993). And this is the work the drag kings interviewed spoke about—-the work of making sure their drag, whether on stage or off worked to transform the ways gender and sexuality were understood in order to open up spaces to do drag, and do life differently.

\section{Final Thoughts}

Contemporary drag kings, therefore, no longer simply invert or reverse gender binaries, but instead "go beyond the simple reversals predicated on binary conceptions of sex and gender to create new gender configurations and new contests in which to understand them” (Surkan, 2003, p. 172). This complex nature of contemporary drag performers and their gendered performativities create new spaces that no longer rely simply on stable, binary gender identities (male/female) and can no longer simply be labeled as either subversive or not.

Drag is not inherently subversive, and at times even has the opposite effect of reinforcing 
Kings reflect on Queerness, Queens, and Questionable Masculinities

binaries, taken-for-granted gendered expectations, and status quo. Yet, the kings' awareness of their own gender and their performances of masculinity increased the chance for their drag to encourage (en)activist practices that worked towards productive alternatives to conventional gender, normative sexualities, dominant power relations, and the potentials of drag (Halberstam, 1998). It is through these en(activist) drag kings that we are moved to new spaces where reconfigurations of "gender-in-process" and gender transformations challenge "reductive readings of female-to-male drag” (Surkan, 2003, p. 183). It is from within these spaces that we can continue to ask critical questions of queerness, Queens, and questionable masculinities. 
Kings reflect on Queerness, Queens, and Questionable Masculinities

\section{References}

Barad, K. (2007). Meeting the universe halfway: Quantum physics and the entanglement of matter and meaning. Durham, NC: Duke University Press.

Barnett, J. T., \& Johnson, C. W. (2013). We are all royalty: Narrative comparisons of a drag queen and king. Journal of Leisure Research, 45(5), 677-694

Baudrillard, J. (1998). Simulacra and simulations. In M. Poster (Ed.), Jean Baudrillard: Selected Writings (pp. 218-234). Stanford, CA: Stanford University Press. (Original work published 1981)

Beemyn, B. G. (2009). Genderqueer. GLBTQ Arts, (1)2, 23-41.

Berbary, L.A. (2011). Post-structural writerly representation: Screenplay as creative analytic practice. Qualitative Inquiry, 17(2), 186-196.

Berbary, L.A. (2015). Creative analytic practices: Onto-episto-theoretical attachments, uses, and constructions within humanist qualitative leisure research. International Leisure Review, 2(4), 27-55.

Boles, J.C. \& Berbary, L.A. (2014). Legacy of our grandmothers: “I’m taking this picture so when you're dead I'll have it.” Qualitative Inquiry, 5(2), 34-28.

Brown, G. M. (Producer), \& Kidron, B. (Director). (1995). To Wong Foo, thanks for everything, Julie Newmar [Motion picture]. United States: Universal Pictures.

Butler, J. (1990). Gender trouble: Feminism and the subversion of identity. New York, NY: Routledge.

Butler, J. (1993). Bodies that matter: On the discursive limits of sex. New York, NY: Routledge.

Connell, R. W. (1995). Masculinities. Cambridge, UK: Polity Press. 
Kings reflect on Queerness, Queens, and Questionable Masculinities

Costa, L., \& Matzner, A. (2007). Male bodies, women's souls: Personal narratives of Thailand's transgendered youth. New York, NY: Hawthorne Press.

Derrida, J. (1976). Of grammatology. Baltimore, MD: The Johns Hopkins University Press.

Dolan, J. (1985). Gender impersonation onstage: Destroying or maintaining the mirror of gender roles? Women and Performance: A Journal of Feminist Theory 2(2), 5-11.

Frye, M. (1983). Politics of reality. Freedom, CA: Crossing Press.

Gagné, P., \& Tewksbury, R. (1996). No “man’s” land: Transgenderism and the stigma of the feminine man. In V. P. Demos \& M. T. Segal (Eds.), Advances in gender research (pp. 115-155). Greenwich, CN: JAI Press.

Garber, M. (1992). Vested interests: Cross-dressing and cultural anxiety. New York, NY: Routledge.

Gysels, M., Shipman, C., \& Higginson, I. J. (2008). Is the qualitative research interview an acceptable medium for research with palliative care patients and carers? BMC Medical Ethics, 9(7), 203-224.

Halberstam, J. (1998). Female masculinity. Durham, NC: Duke University Press.

Hamlin, M., \& Clark, A. (Producers), \& Elliott, S. (Director). (1994). The adventures of Priscilla, queen of the desert [Motion picture]. United States: Gramercy Pictures.

Harris, D. (2005). Diary of a drag queen. New York, NY: Carroll \& Graf Publishers.

Hennessy, R. (1993). Queer theory: A review of the "differences" special issue and Wittig’s "the straight mind”. SIGNS, 118(4), 964-973.

Lewis, S., \& Johnson, C. W. (2011). But it’s not that easy: Negotiating (trans) gender expressions in leisure spaces. Leisure/Loisir, 35(2), 115-132.

Lorber, J. (1994). Paradoxes of gender. New Haven, CT: Yale University Press. 
Kings reflect on Queerness, Queens, and Questionable Masculinities

Lorber, J. (1999). Crossing borders and erasing boundaries: Paradoxes of identity politics. Sociological Focus, 32(4), 355-370.

Mattingly, C., \& Lawlor, M. (2000). Learning from stories: Narrative interviewing in crosscultural research. Scandinavian Journal of Occupational Therapy, 7, 4-14.

Moloney, M., \& Fenstermaker, S. (2002). Performance and accomplishment:

Reconciling feminist conceptions of gender. In S. Fenstermaker \& C. West (Eds.), Doing gender, doing difference (pp. 189-204). New York, NY: Routledge.

Muñoz, J. E. (1999). Disidentifications: Queers of color and the performance of politics. Minneapolis, MN: University of Minnesota Press.

Namaste, V. K. (2005). Sex change, social change: Reflections on identity, institutions and imperialism. Toronto, ON, Canada: Women’s Press.

Newton, E. (1972). Mother camp: Female impersonators in America. Chicago, IL: The University of Chicago Press.

Parry, D. C., \& Johnson, C. W. (2007). Contextualizing leisure research to encompass complexity in lived leisure experience: The need for creative analytic practice. Leisure Sciences, 29, 119-130.

Riessman, C. K. (2007). Narrative methods for the human sciences. Los Angeles, CA: SAGE Publications.

Rupp, L. J., \& Taylor, V. (2003). Drag queens at the 801 Cabaret. Chicago, IL: The University of Chicago Press.

Rupp, L.J, Taylor, V., \& Shapiro, E.L. (2010). Drag queens and drag kings: The difference gender makes. Sexualities, 13(3), 275-294.

Schacht, S. P. (1998). The multiple genders of the court: Issues of identity and 
Kings reflect on Queerness, Queens, and Questionable Masculinities

performance in a drag setting. In S. Schacht \& D. Ewing (Eds.), Feminism and men:

Reconstructing gender relations (pp. 202-224). New York, NY: New York University

Press.

Schacht, S. P. (2000). Gay masculinities in a drag community: Female impersonators and the social construction of “other.” In P. Nardi (Ed.), Gay masculinities (pp. 247-268). Newbury Park, CA: Sage.

Schacht, S. P. (2002a). Four renditions of doing female drag: Feminine appearing conceptual variations of a masculine theme. In P. Gagné \& R. Tewksbury (Eds.), Gendered sexualities (pp. 157-180). New York, NY: JAI Press.

Schacht, S. P. (2002b). Turnabout: Gay drag queens and the masculine embodiment of the feminine. In N. Tuana, W. Cowling, M. Hamington, G. Johnson, \& T. MacMullen (Eds.), Revealing male bodies (pp. 155-170). Bloomington, IN: Indiana University Press.

Schacht, S. P., \& Underwood, L. (2004). The absolutely fabulous but flawlessly customary world of female impersonators. Journal of Homosexuality, 46(3), 1-17.

Squire, C. (2008). Experience-centered and culturally-oriented approaches to narrative. In M. Andrews, C. Squire, \& M. Tamboukou (Eds.), Doing narrative research (pp. 41-63). London, UK: SAGE Publications.

Squire, C., Andrews, M., \& Tamboukou, M. (2008). Introduction: What is narrative research? In M. Andrews, C. Squire, \& M. Tamboukou (Eds.), Doing narrative research (pp. 1-21). London, UK: Sage Publications.

Stuhlmiller, C. M. (2001). Narrative methods in qualitative research: Potential for therapeutic transformation. In K. R. Gilbert (Ed.), The emotional nature of qualitative research (pp. 63-80). Boca Raton, FL: CRC Press LLC. 
Kings reflect on Queerness, Queens, and Questionable Masculinities

Surkan, K. (2003). Drag kings in the new wave. Journal of Homosexuality, 43(3-4), 161-186.

Tewksbury, R. (1993). Men performing as women: Explorations in the world of female impersonators. Sociological Spectrum, 13(4), 465-486.

Tewksbury, R. (1994). Gender construction and the female impersonator: The process of transforming “he” to “she”. Deviant Behavior: An Interdisciplinary Journal, 15(1), 27-43.

Vidal-Ortiz, S. (2008). Transgender and transsexual studies: Sociology’s influence and future steps. Sociology Compass, 2(2), 433-450.

Volcano, D. L. \& Halberstam, J. (1999). The drag king book. London, UK: Serpent's Tail.

Zervigon, A. M. (2009). Drag shows: Drag queens and female impersonators. GLBTQ Arts, (14), 89-103. 